\title{
Sistematização de informações cartográficas de suporte ao plano de gestão e de manejo da zona costeira de Sergipe
}

\author{
Systemization of cartographic information to support the management and management \\ plan for the coastal area of Sergipe.
}

Araújo $^{1}$, H. M.; $\mathrm{Cruz}^{2}, \mathrm{R}$.

heliomarioaraujo@yahoo.com.br

\begin{abstract}
Resumo
O presente trabalho tem como objetivo recuperar a memória do GERCO/SE a partir dos documentos cartográficos produzidos, considerando a apresentação, qualidade e elementos das cartas sínteses parciais e final para subsidiar técnica e administrativamente ao Projeto "Plano de Gestão e de Manejo da Zona Costeira de Sergipe" voltado, especificamente, para o Litoral Sul. A pesquisa abrangeu duas importantes etapas, a saber: levantamento e sistematização de informações cartográficas, compreendendo contatos diretos, através de entrevistas com a equipe da SEPLANTEC, e avaliação do conjunto de procedimentos desenvolvidos associados aos produtos cartográficos elaborados no decênio 1988/1998, abrangendo as metodologias empregadas nas duas fases de implementação do plano de gerenciamento. Do ponto de vista gerencial, os resultados obtidos deverão subsidiar a gestão costeira no âmbito da ADEMA e, do ponto de vista técnico, fornecerá os elementos de suporte ao desenvolvimento do projeto referenciado, delineando o contorno do que está previsto nas diferentes etapas do Diagnóstico Socioambiental e elaboração do Zoneamento Ecológico Econômico.
\end{abstract}

Palavras-chave: Cartografia; Gestão Territorial e Zona Costeira.

\begin{abstract}
This work aims to recover the GERCO / SE memory from cartographic documents produced, considering the performance, quality and features of partial and final syntheses letters to support technically and administratively to the Project "Management Plan and Coastal Zone Management. Sergipe" geared specifically to the South Coast the research covered two important steps, namely collection and systematization of cartographic information, including direct contacts, through interviews with the team SEPLANTEC, and evaluation of the set of developed procedures associated the cartographic products made in the decade 1988/1998, including the methodologies used in the two phases of implementation of the management plan. From a managerial point of view, the results should support coastal management within the ADEMA and from a technical point of view, provide the support elements to the development of the referenced project, delineating the outline of what is expected in the different stages of the Environmental Diagnosis and elaboration of Ecological Economic Zoning.
\end{abstract}

Keywords: Cartography; Management Territorial e Zone Coastal.

\section{INTRODUÇÃO}

O Plano Nacional de Gerenciamento Costeiro (PNGC) tem seus primórdios nas ações da Comissão Interministerial Recursos do Mar (CIRM) na década de setenta do século XX, mais concretamente na Política Nacional para os Recursos do Mar (PNRM). Entretanto, é somente no final da década de oitenta, através da Lei $\mathrm{n}^{\circ}$ 7.661, de 16 de maio de 1988, que o referido plano fora instituído oficialmente abrangendo as três esferas de atuação do governo brasileiro e com uma ótica marcadamente ambiental e espacial visando orientar a utilização racional dos recursos da zona 
costeira, de forma a contribuir para elevar a qualidade de vida de sua população, e a proteção de seu patrimônio natural, histórico, étnico e cultural.

Em Sergipe, coube inicialmente a Secretaria de Estado do Planejamento e da Ciência e Tecnologia (SEPLANTEC) as tarefas de execução do gerenciamento costeiro, que segundo a GEO CONSULTORIA, (2001, p. 1) "seriam melhor desenvolvidas nesta secretaria, em virtude das suas atividades cartográficas e de seu acervo aerofotogramétrico e de mapas, bem como das suas específicas funções de Planejamento e de Pesquisa no Estado”.

Neste sentido, o foco preferencial das atividades iniciais do GERCO/SE foi o Litoral Norte, contemplando 17 municípios, cujo convênio com a SEPLANTEC visava apenas ao macrozoneamento, não cabendo a este órgão desenvolver atividades de gestão e monitoramento, que seriam atribuições de competência da Administração Estadual do Meio Ambiente (ADEMA). Apesar das observações da GEO CONSULTORIA (2001) sobre o acervo cartográfico e das funções específicas do Departamento de cartografia da SEPLANTEC, esse órgão não acompanhou o espetacular avanço das geotecnologias, e por isso não entrou em sintonia com as estratégias do GERCO no Brasil que previa a instalação de Sistemas de Informação de Gerenciamento Costeiro, através da implantação de um setor de Geoprocessamento nas unidades estaduais.

Assim, em 1995 através de termos aditivos comunicados oficialmente ao Ministério do Meio Ambiente (MMA), houve mudança do eixo de prioridade do GERCO/SE para o Litoral Sul abrangendo cinco municípios, com início de uma nova metodologia mais consolidada incorporando o conceito chave de desenvolvimento sustentável, enquadrando-se claramente nas tendências mais contemporâneas de gestão ambiental de ordenamento territorial, sem restringir-se apenas aos mapeamentos como na primeira fase, pois esse cartografismo, sem dúvida, foi uma opção ingênua e simplista para os problemas do gerenciamento costeiro que, infelizmente, a empiria sergipana não soube evitar.

Nessa perspectiva, o presente trabalho tem como objetivo recuperar a memória do GERCO/SE a partir dos documentos cartográficos produzidos na primeira e segunda fase, considerando a apresentação, qualidade e elementos das cartas sínteses parciais e final para subsidiar técnica e administrativamente ao Projeto "Plano de Gestão e de Manejo da Zona Costeira de Sergipe" voltado, especificamente, para o Litoral Sul.

\section{METODOLOGIA}

A pesquisa abrangeu duas importantes etapas, a saber: levantamento e sistematização de informações cartográficas, compreendendo contatos diretos, através de entrevistas, com a equipe da 
SEPLANTEC, anteriormente responsável pela coordenação estadual do Gerenciamento Costeiro, com o propósito de melhor balizar e sistematizar os dados eventualmente apurados e, avaliação do conjunto de procedimentos desenvolvidos associados aos produtos cartográficos elaborados no decênio 1988/1998, abrangendo as metodologias empregadas nas duas fases de implementação do GERCO/SE.

O uso prático do roteiro metodológico norteador, fundamentado nas experiências de autores russos e franceses (SOTCHAVA, 1963; BERTRAND, 1972; TRICART, 1978) com adaptação a realidade local, culminou para Sergipe na elaboração de vários documentos cartográficos, como segue: a) Carta de Geomorfologia; b) Carta de Qualidade e Disponibilidade dos Recursos Hidrogeológicos; c) Carta de Uso do Solo, Vegetação e Utilização da Terra; d) Carta de Diagnóstico Socioeconômico; e) Carta de Potencialidade dos Recursos Naturais e Ambientais; f) Carta de Limitações e Restrições ao Uso do Território e; g) Carta de Diagnóstico Socioambiental (Qualidade Ambiental, Riscos Ambientais e Conflitos de Uso).

Neste sentido, resguardando os princípios e recomendações apontados pela cartografia temática, levou-se em consideração na análise cartográfica, a semiologia gráfica, bem como a apresentação do conteúdo gráfico e verbal, já que é consenso na Cartografia a inserção de pequenos cartogramas, croquis e outras ilustrações, para evitar um eventual risco de "poluição visual" de uma determinada carta-síntese em decorrência da realidade multifacetada dos cenários alternativos existentes no Litoral Sul Sergipano.

\section{RESULTADOS E DISCUSSÃO}

\section{1- Breves reflexões teórico/técnicas sobre os produtos cartográficos elaborados}

O mapa é um instrumento fundamental para pensar, decidir, planejar e agir racionalmente sobre o espaço, principalmente quando a escala ultrapassa a dimensão do lugar imediato, do lugar de vida do sujeito e, o mapa, então, possibilita pensar o espaço ausente, distante, desconhecido empiricamente (MIRANDA, 2001).

Seguindo essa lógica de raciocínio, é notória, a compreensão de que a evolução da ciência e tecnologia possibilitou o desenvolvimento de novas formas de se registrar informações espaciais, a exemplo das fotografias aéreas e das imagens de satélite. Mas, no entanto, essas novas técnicas, que têm suas vantagens e aplicações específicas de grande importância nos dias atuais, não possuem a seletividade do mapa, primado pela cartografia, tanto que, ao invés de substituí-lo, contribuíram 
sobremaneira para seu aperfeiçoamento, possibilitando maior grau de precisão dos documentos cartográficos.

Enquanto arte, um mapa deve respeitar determinados aspectos estéticos, uma vez que se trata de um documento que precisa ser agradável ao olhar, razão pela qual necessita de uma boa disposição de seus elementos (cores, símbolos, traços, letreiro, legenda, margens, entre outros), visto ser a arte sinônima de complexidade, muito embora a depender de sua finalidade, o mapa possa ser ou não mais complexo. E sendo grande o número de informações, não se deve esquecer da clareza, da harmonia entre os seus componentes e, bem assim da simplicidade.

\subsection{1- Da qualidade da representação cartográfica das cartas temáticas}

A elaboração de um documento cartográfico constitui um processo bastante complexo. Seja de forma convencional e/ou em meio digital, a sua execução deve, obrigatoriamente, observar um mínimo de regras para torna-los, ao mesmo tempo, fácil de compreender e útil para explorá-lo. Assim, as qualidades de um bom mapa são medidas por sua eficácia, precisão, expressão e legibilidade, requisitos tais inexistentes nas representações cartográficas confeccionadas para o setor costeiro do Litoral Sul Sergipano, pois:

Quanto à eficácia as cartas, a priori, deveriam estar corretas, pois um mapa é considerado eficaz quando é perfeitamente adaptado ao seu objetivo nos limites de sua escala e de seu sistema de projeção. Deveriam ser estéticas e agradáveis, de olhar registrável na memória além de se apresentarem sóbrias, sem sobrecargas visuais inúteis. A eficácia é constatada pela facilidade de leitura, bem como do tempo mínimo necessário para dele retirar o máximo de esclarecimentos de qualidade. Neste sentido, entendemos que o melhor mapa é o que requer menos esforço, no mínimo de tempo, para atingir o objetivo visado, muito longe da expectativa das cartas elaboradas, a exemplo das sínteses ambientais parciais (Limitações ao Uso do Território, Potencialidades dos Recursos Naturais e Ambientais, e Riscos Ambientais e Conflitos de Uso do Solo, entre outras).

Quanto à precisão que nada mais é do que reduzir o erro gráfico ao mínimo, leva-se em conta a escala e os instrumentos utilizados no momento do levantamento e da constante redação do documento.

A precisão de um mapa reside, em primeiro lugar, na indicação e no traçado dos diversos elementos gráficos. Naturalmente ela depende da escala e diminui com ela. As cartas supracitadas, como exemplificação do item anterior, não preservam com exatidão esses requisitos indispensáveis a uma boa qualificação do produto cartográfico produzido. Seja como for, a redução da escala de representação dos fenômenos previamente selecionados e já trabalhados em uma escala maior 
(1:25.000), obriga o profissional diretamente envolvido com a sua elaboração, a empregar mais sinais convencionais, que são cada vez mais ilegíveis e, portanto, cada vez menos precisos, pois na maioria das vezes, para chamar a atenção é preciso exagerar certas superfícies de maneira a tornálas visíveis, quando, então, elas são transcritas por símbolos geométricos exagerados.

Alerta Fernand Joly (1979) que se o mapa é preciso, deve também ser exato e fiel. Exato pela isenção de qualquer erro de documentação, de localização ou de interpretação. Fiel pela precisão de seus dados de maneira correta e de acordo com a realidade dos levantamentos compatíveis com a sua escala e seu objetivo. Sendo, entretanto, a precisão, fidelidade e exatidão, as qualidades básicas, científicas e legais, que correspondem às condições de emprego ideal do mapa e ao crédito que se lhe pode dar.

Quanto à expressão as cartas sínteses ambientais parciais, final e Diagnóstico Socioambiental; Qualidade e Disponibilidade dos Recursos Hidrogeológicos; Uso do Solo, Vegetação e Utilização da Terra; Geomorfologia e Diagnóstico Socioeconômico, não atinaram cuidadosamente para o uso das variáveis visuais, principalmente a cor, contemplada por todas elas, faltando-lhe em sua aplicação boa dose de bom senso para evitar todo simbolismo confuso ou equivocado no processo de comunicação da mensagem graficada.

Considera-se um mapa expressivo, quando atrai convenientemente a atenção do leitor para os mais significativos aspectos do tema tratado, o que não ocorre com as referidas cartas temáticas, uma vez que todas elas estão eivadas do que denomina Ogata (1995) “poluição visual”. A expressão é uma parte importante da estética de uma carta temática, como também é uma parte significativa do seu valor científico. Em cartografia temática, a expressão é uma qualidade relevante, pois o objetivo essencial é, então, fornecer uma imagem seletiva e coerente dos fatos representados e de suas correlações.

A evidência dessa problemática bastante contundente, nas cartas elaboradas, atribui-se ao fato de não ter havido uma verdadeira intervenção do profissional técnico responsável pela sua construção no momento da digitalização das cartas temáticas originais com o auxílio da ferramenta computadorizada, culminando, enfim, com deficiência de plotagem (manchas coloridas, símbolos e legendas). Esse acompanhamento residiria tanto na aliança dos procedimentos gráficos, quanto na sua escolha. Em geral, bastaria aplicar nesse objetivo, algumas regras de lógica e bom senso, utilizando representações sugestivas, aproximando o que é comparável, contrastando o que não é semelhante, classificando e ordenando corretamente os valores.

A legibilidade de uma carta observa as mesmas regras de legibilidade de um texto ou audibilidade de um discurso. A carta Diagnóstico Socioeconômico, por exemplo apresenta uma densidade gráfica muito grande, deixando transmitir sobrecarga visual do documento. Em 
decorrência da reunião de várias informações básicas utilizadas nesse documento, sugere-se como previsto na metodologia aplicada ao macrozoneamento, seu desmembramento em outros mapas adaptado às possibilidades científicas e às capacidades técnicas dos computadores. A regra fundamental é que o documento não seja sobrecarregado nem ilegível. A legibilidade reveste-se na qualidade que permite a uma informação procurada ser fácil e imediatamente percebida e memorizada sem esforço, em qualquer nível de leitura.

Para isso, é preciso clareza da mensagem e seletividade dos meios de expressão ou emprego adequando às variáveis visuais. Assim, tanto quanto o Diagnóstico Socioeconômico, a carta síntese de Uso do Solo, Vegetação e Utilização da Terra, comportando vinte e uma categorias de uso, deixa de ser legível, uma vez que não se consegue no nível dos detalhes, isolar à primeira vista, a informação desejada, nem muito menos captar, no nível do conjunto, as relações existentes entre as manchas coloridas elementares. Em nível elementar, as variáveis da retina deverão ser escolhidas em função de seu valor simbólico, bem como em razão de suas propriedades dissociativas. Em tese, a legibilidade de um mapa deve levar em consideração os limites de percepção (neste caso visual) que não se devem jamais transgredir.

\subsection{2 - Dos elementos das cartas sínteses parcial e final}

\section{a) Título e legenda}

Como partes integrantes das cartas, o título indica o assunto abordado da carta e a legenda permite a compreensão interna dos documentos e do seu simbolismo.

Um título completo deve informar: o que? Onde? Quando? Em todas as cartas temáticas confeccionadas, esse importante elemento de identificação dos documentos está representado de forma incompleta, não respondendo a última pergunta: quando? Deve ser curto, completo e preciso, a fim de ser rapidamente compreendido. Apesar de estar escrito com letreiro destacado, deve ser colocado dentro do quadro de representação (preferencialmente no alto e a esquerda das cartas) já que a projeção do mapa do Litoral Sul sobre a folha o permite.

A legenda, por sua vez, não deve ser considerada como mero inventário ou lista desordenada, exibindo sinais escolhidos ao acaso. Objetiva facilitar a leitura do documento, ajudando ao leitor encontrar rapidamente os objetos e os fatos cartografados. Ainda permitindo a percepção das variações.

Quanto a esse elemento, apreende-se que as sete cartas temáticas apresentam problemas os mais diversos. Assim, as cartas de Geomorfologia e Uso do Solo, Vegetação e Utilização da Terra, não comportam um cabeçalho de legenda, o qual não deve ser confundido com cabeçalho de um título. O cabeçalho de legenda, além de identificar sumariamente os dados representados, mostra como os símbolos devem ser interpretados evitando redundância com o título ou mesmo consistindo 
em uma parte desse mesmo título. Na carta de Geomorfologia, por exemplo, o leitor que não tenha habilidade técnica com essa área do conhecimento científico, muito dificilmente saberá distinguir nesse tipo de representação cartográfica, uma unidade geomorfológica, de um acidente geográfico. Na mesma direção, confunde-se uso do solo com a utilização da terra.

As cartas temáticas que versam sobre: Qualidade Ambiental, Riscos Ambientais e Conflitos de Uso; Potencialidades dos Recursos Naturais e Ambientais; Qualidade e Disponibilidade dos Recursos Hidrogeológicos; Limitações e Restrições ao Uso do Território e Diagnóstico Socioeconômico, apresentam símbolos ou manchas coloridas na legenda, às vezes sem a devida correspondência no interior do mapa, como também fenômenos diferentes plotados sobre a mesma carta, representados com a mesma tonalidade da variável cor (etenoduto, gasoduto e transporte por dutos) e, o uso de convenções cartográficas em dissenso com o padrão internacionalmente adotado e reconhecido como se observa a simbologia empregada para representar a indústria isolada (devendo-se utilizar o símbolo de uma indústria com chaminé), bem como a cor verde em tom claro, não sendo apropriada para representar as rodovias estaduais conforme consta na implantação de algumas cartas, devendo-se fazer uso do vermelho. Outro fator importante a se considerar diz respeito a não padronização de convenções para representar o mesmo fenômeno em cartas divergentes, como no caso da energia.

Ressalte-se que, além da variável da retina forma ter sido largamente utilizada para representar qualitativamente os fenômenos associando-os ou selecionando-os no interior de algumas cartas específicas, como as de Qualidade Ambiental, Riscos Ambientais e Conflitos de Uso e Diagnóstico Socioeconômico, relacionada aos modos de implantação pontual, linear e zonal, é sem sombra de dúvidas a variável visual cor que perpassou com mais amplitude em todos os mapas produzidos, merecendo nessa análise uma retomada mais específica a respeito.

Para tanto, os níveis de informações consideradas nas cartas temáticas após a escolha do modo de implantação dos símbolos durante a fase de planejamento delas, como o qualitativo, seletivo e associativo, permitiram sobremaneira o emprego usual das manchas coloridas, porém sem haver atenção a harmonia das cores quando da confecção dos mapas.

A harmonia pelas cores opostas deveria estar presente com bastante nitidez e clareza nas cartas de Uso do Solo, Vegetação e Utilização da Terra; Limitações e Restrições ao Uso do Território; Qualidade Ambiental, Riscos Ambientais e Conflitos de Uso, pois nelas existe a intenção de mostrar a distinção entre os fenômenos representados. Essa oposição à cor é verificável na Rosa cromática, como o laranja por exemplo, que se encontra no vértice contrário ao do azul (DUARTE, 2002).

\section{b) Escala e letreiro}


Um dos aspectos fundamentais no alcance dos objetivos propostos para o estudo diagnóstico socioambiental do Litoral Sul, foi sem dúvida, o da definição da escala de trabalho para não perder de vista a riqueza das análises que deveriam ter sido elaboradas caso a representação cartográfica não fosse compatível com o detalhamento pretendido.

Neste sentido, percebe-se que a equipe conveniada (SEPLANTEC) fez uso das categorias taxonômicas de Caileeux e Tricart, parcialmente extraídas do estudo "Teoria e Clima urbano" de Monteiro (1966). A escala de 1:100.000 e 1:25.000 utilizadas nas representações cartográficas, dentro das categorias taxonômicas, apresentam-se na $5^{\text {a }}$ ordem de grandeza que equivale às informações geográficas locais. Seja como for, esse tratamento de escala se constitui em importante ordem taxonômica, ao ponto de permitir detalhamento de estudo mais específico com mapeamento em escalas maiores.

As representações cartográficas acham-se na escala padronizada de 1:100.000, dificultando inclusive o manuseio em decorrência do excessivo tamanho da área útil do papel.

Embora as cartas produzidas apresentem escalas gráficas (para correções) e numéricas, a única escala a constar dentro de uma representação temática é a escala gráfica, a fim de evitar que alterações mecânicas posteriores conservem a indicação numérica de uma escala que já não é a mesma do mapa original.

A colocação do letreiro sobre mapas é um dos principais elementos da lógica visual devido a sua importância linguística, prática e estética. Logo, sua realização correta ajuda na comunicação da informação, e quando acontece o contrário conduz à confusão e dispersão do leitor.

Em atenção aos princípios gerais para conduzir à obtenção de clareza e legibilidade em uma carta, nota-se que em determinadas cartas como a de Limitações e Restrições ao Uso do Território, Geomorfologia, Diagnóstico Socioeconômico, Uso do Solo, Vegetação e Utilização da Terra, os nomes não são facilmente legíveis, face à densidade de grafismos e dosagem das cores utilizadas.

A carta de Qualidade Ambiental, Riscos Ambientais e Conflitos de Uso, em comparação com as demais, é a que apresenta maior problema nessa ordem, pois além de comportar letras de tamanho bastante reduzido tornando-se ilegíveis algumas denominações, entre elas as das sedes municipais, principais rios, praias e oceano, encontram-se sem nenhuma coloração dificultando ainda mais sua leitura.

No mais, todos os documentos cartográficos já padecem de dosagem e/ou ajuste no tamanho da letra a partir da identificação dos objetos representáveis na legenda.

\section{c) Fonte, orientação e localização geográfica}


Os documentos cartográficos trazem a fonte, de uso obrigatório e recomendável pela cartografia, sendo através dela que o leitor se inteira ou toma conhecimento da base de elaboração das cartas. Embora haja preferência para sua disposição na parte inferior do mapa, esse elemento ainda não está muito bem posicionado nas cartas.

Para elaboração utilizou-se fotografias aéreas na escala de 1:16.500, ano de 1988, disponíveis na COHIDRO/SE e na escala de 1:25.000, ano de 1986 provenientes da SEPLAN/SE e cartografia básica das cartas topográficas da SUEDENE na escala de 1:100.000, ano de 1974.

Todo mapa deve permitir que o leitor não familiarizado com a área alí representada, seja capaz de extrair com a máxima precisão possível a localização desse lugar e identifica-lo. Para isso, ao realizar um trabalho científico, o pesquisador incluirá um mapa de referência básica, localizando a área dentro de um conjunto mais amplo através de um encarte em um conjunto maior. A propósito, as cartas em análises trazem a situação da folha no Estado, em algumas delas merecendo correções, mas não apresentam divisão administrativa e tão pouco o sistema UTM (Universal Transversa de Mercator) que não é uma projeção cartográfica, mas um sistema baseado na projeção Universal Transversa de Mercator.

\subsection{3 - Da apresentação dos documentos cartográficos}

As construções gráficas são apresentadas no plano do papel que atende as dimensões e formatos condicionados pelo contexto literário do qual fazem parte ou por condicionantes definidas pelo pesquisador. O arranjo espacial do conjunto gráfico e elementos externos à representação (conteúdo gráfico e verbal dos mapas) devem manter o equilíbrio entre a representação propriamente dita (área mapeada) e a estética do documento.

Geralmente o pesquisador prefere trabalhar com uma escala maior e após concluída a composição da representação cartográfica submete o documento a uma redução fotográfica que se enquadre nas dimensões estabelecidas para apresentação final. Não existe qualquer dificuldade para esse procedimento. Por esse motivo, nada justifica o fato desatencioso, sob o ponto de vista do arranjo estético e da forma, nos produtos cartográficos elaborados. Sobre esse último percebe-se que o formato do documento aproximando-se da figura quadrangular não recepciona esteticamente o desenho em planta dos municípios integrantes do Litoral Sul e dos elementos de identificação (título, legenda, escala, fonte, encarte, entre outros).

A opção do documento em formato retangular parece mais sugestivo e complacente aos princípios gerais da cartografia porque evita um problema facilmente corrigível. 
Recomenda-se, portanto, atentar para a estrutura de uma boa representação gráfica, devendo-se incluir o nome de sua autoria não perceptível nas cartas sínteses, exceto nos Diagnósticos Socioeconômico e Ambiental.

\section{CONSIDERAÇÕES FINAIS}

A consulta realizada nos arquivos do Departamento de Estudos Geográficos e Cartografia (DEGEC) da SUPES/SEPLANTEC ensejou concluir que:

a) Durante os seis primeiros anos (1988 - 1994) em que basicamente perdurou os estudos com essa metodologia inicial, a produção cartográfica foi por demais incipiente limitada a cartografia convencional de desenho manual, cujos documentos na melhor expressão da linguagem cartográfica “esboços" acham-se atualmente em papel vegetal;

b) Tais esboços cartográficos com dados extremamente relevantes sob o ponto de vista de interesse do GERCO e que versam sobre Geologia, Climatologia, Declividade, Qualidade e Disponibilidade dos Recursos Hidrogeológicos, Planos, Projetos e Zoneamentos existentes, Vegetação e Uso do Solo, deveriam ter sido submetidos à técnica moderna de digitalização desses originais, criando arquivos gráficos em meio digital, de sorte que permitisse a saída gráfica via computador plotadas com manchas coloridas, símbolos e legendas. Por outro lado, a formação do arquivo gráfico em meio magnético tem a vantagem de permitir que a cartografia seja constantemente atualizada evitando tornar-se um registro absoleto;

c) No mais, nos parece que os objetivos delineados para essa primeira fase dos estudos contemplados pela cartografia fluíram em parte, pois os desenhos manuais em vegetal existentes (arquivados em mapoteca) não satisfazem os requisitos básicos exigidos pela cartografia temática como produto final de uma representação gráfica de boa qualidade, assim considerando a eficácia, precisão, expressão e legibilidade.

Em 1994 ao iniciar uma nova etapa dos trabalhos quando o Programa já estava sob o comando do Ministério do Meio Ambiente (MMA) a Coordenação Nacional de Gerenciamento Costeiro divulgou nova metodologia de macrozoneamento seguida pelos estados conveniados. Isso representou para Sergipe mudança de sua área de atuação substituindo o Litoral Norte, pelo Litoral Sul, com área de abrangência extensiva a cinco municípios (São Cristóvão, Itaporanga D’Ajuda, Estância, Santa Luzia do Itanhy e Indiaroba).

Assim, a condução dos estudos visando contemplar essa nova fase metodológica apoiada na abordagem Geossistêmica, culminou, inicialmente, com os levantamentos de variáveis do meio 
físico e socioeconômico, na perspectiva de elaboração das sínteses ambientais parciais e final (Diagnóstico socioambiental).

\section{REFERÊNCIAS}

BERTRAND, G. Paysage et geographie physique globale: esquise méthodologique. Reveu géographyque des phyrenées et du sud-oest. v. 39, nº 03, Tolouse. 1968/1972.

DUARTE, Paulo A. Fundamentos de cartografia. Florianópolis, Ed. UFSC, 2002.

GEO CONSULTORIA, Zoneamento Ecológico-Econômico do litoral Sul de Sergipe. Aracaju, 2001.

JOLY, F. La cartographie, Press Universitaire de France. Paris, 1979.

MIRANDA, Sergio L. A noção de curva de nível no modelo tridimensional, In: Boletim de Geografia, v. 19, nº 02, Maringá: VEMA/DGE, 2001.

MONTEIRO, Carlos A. de F. Teoria e clima urbano. São Paulo, Instituto de geografia, (série tese e monografia) $n^{\circ} 25,1966$.

OGATA, M. G. Macrozoneamento costeiro: aspectos metodológicos, MMA, Brasília, 1995.

Recebido em: 14/08/2016

Aceito para publicação em: 01/10/2016 